\title{
Assessment of The Electrical Systems Interconnection in The Arab World
}

\author{
M.H. Abderrazzaq
}

Hijjawi Faculty for Engineering Technology, Yarmouk University, Irbid 21110, Jordan, Email: abder@maktoob.com.

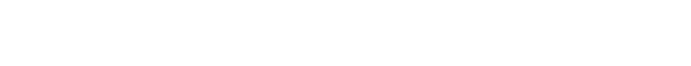

\section{محمد عبدالرزق}

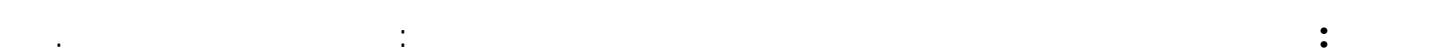

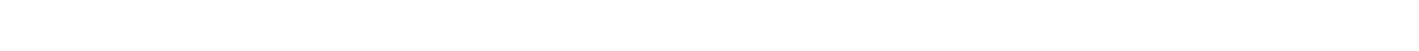

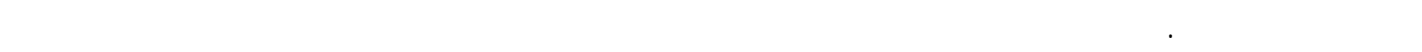

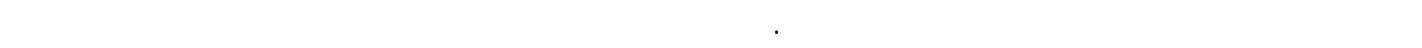

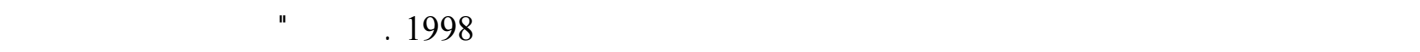
الصعوبات الفنية الني إما ولجهت مشروع الربط الكهربائي في مرلحله الأولى أو التي يتوقع أن تولجهه في مرلحله المسنقبلية .

\begin{abstract}
The international trend of interconnecting electric power systems has two dimensions; economical and technical. Electric power systems in the Arab World are not only eligible, but in need for having a unified power grid. The potentials, status and conditions of the existing and future interconnections in this region are overviewed. The development of the six countries interconnection project, including the completed phase of Jordan-Egypt submarine link, is discussed in details. Finally, the main technical problems, which either faced the first stages of the project or expected to face the interconnected systems in the subsequent stages, are highlighted.
\end{abstract}

KEYWORDS: Energy, Interconnection, Grid, Submarine Cable, Overhead lines.

\section{Introduction}

$\mathbf{E}$ lectricity is the most flexible form of energy and it is considered one of the most significant indicators of economic growth. The demand for electrical energy is growing at a fast rate worldwide. However, the available resources are limited and not uniformly distributed among the countries. Therefore, it is necessary to manage these resources and utilize them in optimal form. The transmission of energy among the countries is achieved either in the form of crude fuel or as electrical energy. The later form of energy transmission is found more flexible, economical and reliable for adjacent countries, planning to promote their future cooperation in the energy sector.

The interconnection of electric power has been a well-established practice since the development of the three phase AC systems (Ibrahim, 1996). Therefore, many existing interconnections with transmission lines running across territories, having different climatic conditions and topographies, were employed a long time ago. The factors behind these interconnections, and which encouraged the countries to get involve in these projects, were mainly of economical and technical nature (Sackey and Zakhary, 1996). The interconnection allows for sharing the reserve margins between electrical systems. Consequently countries will not need to build as many generating stations on their territories. Moreover, the exchange of electrical energy in normal and emergency circumstances should improve the economies of national power systems and provide a 


\section{M.H. ABDERRAZZAQ}

high degree of security to all sides of the interconnection. Generally, to benefit from all these advantages, the interconnection project requires thorough investigation followed by a solid preparation and strong commitment.

The electric systems in the Arab World are in need of interconnections more than other systems in the region. There are several Arab countries whose national networks are not yet interconnected. Unfortunately, the plans proposed to set up unified power grids in these countries many years ago progressed rather slowly. Despite this difficulty, the power systems in the Arab countries are more eligible for interconnection than other systems in the world due to the availability of all energy sources in the area and the ease of transmitting this energy between neighboring countries. The positive aspects of interconnection, and its impact on improving the integration capability of the economic systems and reinforcing the national grids, were clear to all decision makers in the Arab countries three decades ago. However, a long time has elapsed before started thinking seriously about the vitality of the interconnection project and only a few of them are now actually working in this direction.

In this work, the current interconnection projects in the Arab world are overviewed and evaluated. The technical difficulties of the new interconnections are discussed based on the most recent available data. The paper will highlight the various aspects of the project linking Egypt, Jordan, Syria, Lebanon, Iraq and Turkey, which is currently called (EIJLST) interconnection project.

\section{Overview of the Interconnections Among the Arab Countries}

Some electric systems in the adjacent Arab countries have been connected for years. However, these links were limited in capacity and the amount of the exchangeable energy was rather small and fluctuated from year to year (AMRO, 1997). This fluctuation was mainly attributed to political reasons and only in some cases to the technical difficulties.

Moreover, a serious look at these links shows that they have been established in response to some imminent and emergency cases, which made them not adequately planned and not designed as permanent interconnections. As a result, these weak links were incapable of carrying high quantities of electrical energy from one system to another. This in fact leads to the real need for new reliable interconnections linking all countries in the region. Figures 1 and 2 show the maps of Arab countries, with some links connecting neighboring systems or planned to connect them.

In fact, the international trend in this direction has greatly encouraged the planners and designers of electric systems in the Arab countries to go faster in the way of establishing a unified Arab network. One of the largest regional projects in this direction was the six countries interconnection project, EIJLST. These countries are characterized by their location and by having vital terminal points with networks in Europe, Asia and Africa.

In fact, the first and second parts of the interconnection have already been completed with the electric power networks of Egypt, Jordan and Syria being linked. The EgyptJordan link via the Red Sea was the real technical and economical challenge to the main EIJLST interconnection project. Despite the technical difficulties, which faced this project in the initial stage and which were mainly related to the $400 \mathrm{kV}$ oil-filled submarine cable, the link is currently serving the interconnection effectively. Figure 3 illustrates the main constituents of this cable, which was of special design to withstand the extreme mechanical load, caused by the topographical and unusual depths of the Red Sea, (Abderrazzaq and Alzahawi, 1996). Figure 4 shows a simplified diagram of the Jordan-Egypt link. On the Egyptian side, it was necessary to connect Taba substation with Suez power station via a $400 \mathrm{kV}, 500 \mathrm{MW}, 330 \mathrm{~km}$ transmission line, whereas in the 


\section{ASSESSMENT OF THE ELECTRIC SYSTEMS INTERCONNECTION}

Jordanian side it was necessary to establish a new $400 \mathrm{kV}$ substation and to reinforce the Aqaba thermal power station with extra generating units. The submarine cable connected between Taba and Aqaba substations is $13 \mathrm{~km}$ long and was laid at a depth of $850 \mathrm{~m}$ underwater. Currently, the exchangeable energy between Egypt and Jordan reaches $130 \mathrm{MW}$, but it is expected to be in the order of $350 \mathrm{MW}$ after the completion of the project and linking with other countries.

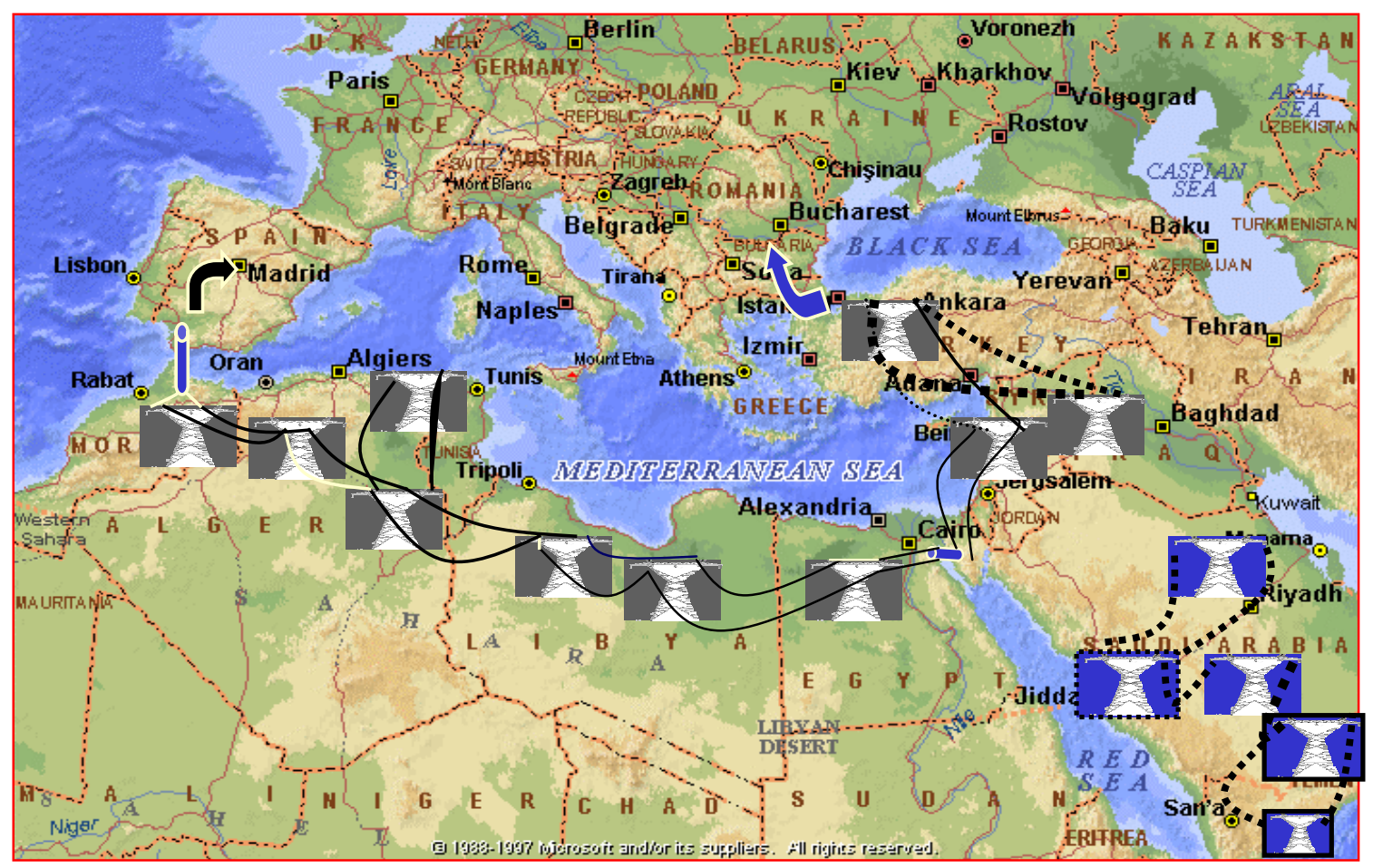

Figure 1. The map of Arab countries with existing and future interconnection.

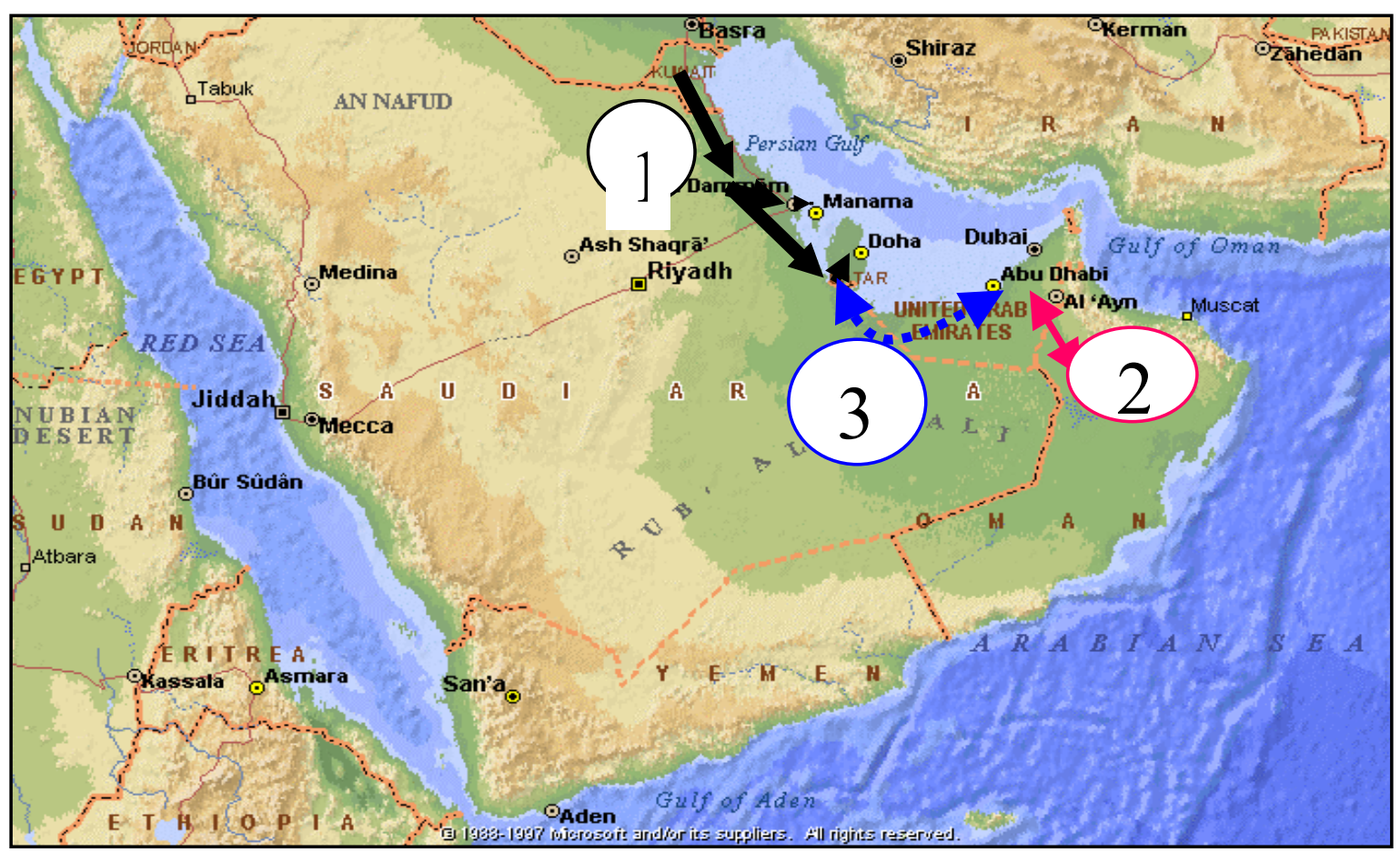

Figure 2. The stages of the future interconnections among the GCC countries. 


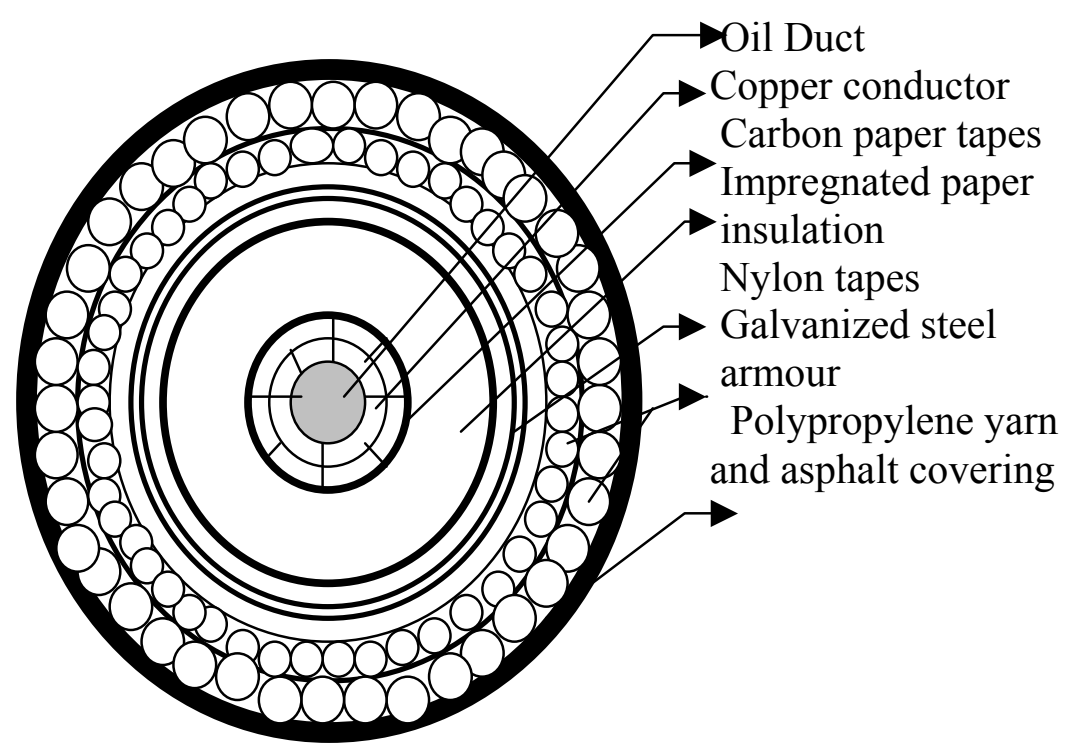

Figure 3. Main constituents of the $400 \mathrm{kV}$, oil-filled submarine cable.

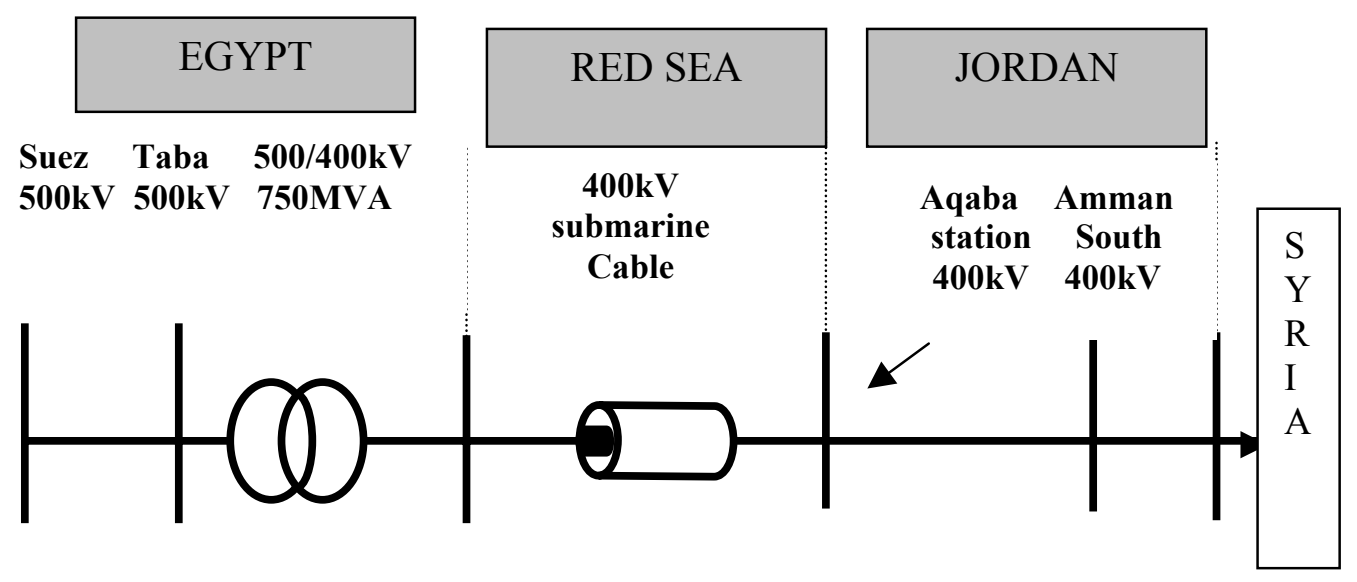

Figure 4. Simplified diagram of the Egypt-Jordan interconnection link.

On the other side of the Arab World, a number of vital projects are currently being given increased attention by decision makers. Spain is already supplying Morocco with electricity via a $400 \mathrm{kV}, 26 \mathrm{~km}$ and $615 \mathrm{~m}$ deep submarine cable, established between these two countries. Morocco's grid is also interconnected with Algeria and Tunisia, whereas Egypt is linked to Libya by a $220 \mathrm{kV}$ power line, which allows for $180 \mathrm{MW}$ to be exchanged between the two countries. This power line covers a distance of $420 \mathrm{~km}$ along the north-western coast from Alexandria to Salloum on the Libyan border. There are also plans for the Egyptian and Libyan power networks to be linked to Europe across the Mediterranean through Italy. In addition to the eastern link with Europe via Turkey, Egypt and Libya can exchange power with Europe through Italy and Spain. For this purpose, a $500 \mathrm{kV}$ network is being planned linking Egypt and Libya. A $400 \mathrm{kV}$ network is also being planned to interconnect Libya, Tunisia, Algeria and Morocco, which are currently only connected by $220 \mathrm{kV}$ lines. This will form the backbone of a Mediterranean Power Pool (MPP), which will link the grids of the Middle East, North Africa and Europe. According to GOUWS (1999) the anticipated completion date of the MPP is 2015. 


\section{ASSESSMENT OF THE ELECTRIC SYSTEMS INTERCONNECTION}

The electric systems in the Gulf region have been growing rapidly in the last two decades. The presence of oil prevents any shortage in power plants and spinning reserves in these countries. Despite these conveniences, the electric systems in the Gulf countries are of great need to have a unified power grid for emergency purposes, for enhancing national and local networks and for saving investments, spent in building new power stations. It is worth mentioning here, that a number of promising steps have been taken by all members of the Gulf Cooperative Council (GCC) countries in this direction. The first phase in the Gulf interconnection will link Saudi Arabia, Kuwait, Bahrain and Qatar in a $400 \mathrm{kV}$ one grid, while the second stage integrates Oman and the UAE into the overall grid as shown in Figure 2. The sharing of the transmitted power is based on a strategic criterion and mutual benefits of each country (Ibrahim, 1996). However, a number of hurdles could cause a delay in the completion of the interconnection in this region. Among these problems are the relatively long distances between the countries, the presence of some unlinked national grids and the difference in power frequency between Saudi Arabia and other Gulf countries. It is worth mentioning here, that these problems will not hider the Gulf countries from going on with their recent huge plans and investments to reinforce their national grids and to make this interconnection more reliable and robust.

\section{Technical Considerations and Network Studies}

The power systems in the Arab countries have been established and developed using the experience and consultations of various foreign companies. This fact is clear from the differences in the design and ratings of the equipment used and the standards applied in the Arab countries. These systems have been working separately for decades without having serious complaints. However, when these systems become a part of the interconnection, serious technical difficulties are expected to occur. One of the problems which faced the initial studies of interconnection was the lack of information, records and data, which are considered of great importance for many studies such as protection, insulation, coordination and stability studies. Therefore, it is difficult to answer the question whether a specific analysis has been performed in the design stage or which measures have been made to test the equipment before putting it in operation. To avoid this situation in future, the manufacturer should carefully perform the commissioning test of the facilities, by installing the suitable recorders and analyzing the test measurements precisely (EDF Report, 1998). The main technical difficulties which appeared during the initial stages of interconnection or might appear in future, as shown by the simulation studies, can be summarized as follows:

\subsection{Power Exchange Problems}

The power exchange limits are determined for the worst case, which can face the interconnected system during its operation. Therefore, the criteria applied during the study stage of the project were based on the following facts (EDF Report, 1998) : Firstly, the systems loaded at the maximum power exchange had to satisfy the security rules following the tripping of one internal element. Secondly, the tripping of the interconnection link, loaded at the maximum power exchange, should not lead to shedding more than the first step of the underfrequency load shedding scheme. Finally, the tripping of the interconnection link loaded at the maximum power exchange should not lead to unacceptable overfrequency or overvoltage in power systems. The minimum value of the voltage limit, in many cases, cannot be modified to allow more imported power. Table 1 provide some values for the possible exchanged power among the systems of Egypt, Jordan, Syria and Turkey. Other countries will be included in future in the subsequent stages of this interconnection. 
Table 1: Expected values of the interchangeable energy among the EJLST countries.

\begin{tabular}{|c|c|c|c|c|}
\hline Limits in MW & $\begin{array}{c}\text { Egypt can } \\
\text { Import }\end{array}$ & $\begin{array}{c}\text { Jordan can } \\
\text { Import }\end{array}$ & $\begin{array}{c}\text { Syria can } \\
\text { Import }\end{array}$ & $\begin{array}{c}\text { Turkey can } \\
\text { Import }\end{array}$ \\
\hline From Egypt & & 50 & 350 & 350 \\
\hline From Jordan & 260 & & 350 & 300 \\
\hline From Syria & 250 & 50 & & 500 \\
\hline From Turkey & 220 & 50 & 620 & 450 \\
\hline From E+J & & & 400 & \\
\hline From S+T & 250 & 50 & & 700 \\
\hline From J+S+T & 260 & & & \\
\hline From E+J+T & & & & \\
\hline
\end{tabular}

\subsection{Oscillations}

Small inter-area oscillations could appear following the conditions of a short circuit on one of the interconnection transmission lines. System configuration, involving different combinations of generators, overhead transmission lines and submarine cables may result in such type of problems. The simulations performed in the first stage of the EIJLST interconnection between Jordan and Egypt showed that these oscillations could be well damped with the existing parameters on both sides. Moreover, reinforcing the existing tie lines and enhancing internal systems are important means for improving the behavior of interconnected systems.

\subsection{Overvoltages}

One of the problems which frequently occurs during the operation of the interconnection link is the long duration temporary overvoltages. This case is usually developed when transformers are switched in at $\mathrm{AC}$ fault clearing or as a consequence of voltage rises due to load rejection. The harmonic currents, generated by the saturated transformer, may coincide with resonance impedance points in the system and as a consequence harmonic voltages of high amplitudes will build up. This could cause unusual overvoltages of high magnitudes. Resonant overvoltages are particularly of great interest, not only when transformers have to be re-energized or during commissioning tests of the transformers, but also each time the interconnection link is put into service again after tripping. In the case of a near fault clearance in normal operation, the risk of an overvoltage occurrence also exists. In this case, the voltage significantly decreases during the fault and suddenly reappears upon fault clearance, which can be considered in some conditions almost equivalent to re-energization (EDF Report, 1998).

The steady state overvoltages, associated with the interconnection link must be examined with no power exchange between connected systems, which is in fact the worst situation to be studied. Simulations are usually performed for faults at different locations along the interconnection link. The necessary studies could be performed using specialized computer programs such as Electromagnetic Transient Program (EMTP), Transient Network Analyzers (TNA) and other simulators. According to the obtained results and to avoid the equipment damage, the suitable protection system has to be proposed. Therefore, the studies performed for Egypt-Jordan link, came with a proposal to install overvoltage relays, set at $570 \mathrm{kV}$ at the Suez substation on the Abu Zabal-Suez line and at Taba substation on the Suez-Taba line. However, on the Jordan side it was necessary to install an intertripping relays at Amman South substation, on the $400 \mathrm{kV}$ Aqaba-Amman South line.

\subsection{Frequency Excursions}

When the rating of the AC transmission of the interconnection links is considerably higher than the small system load, severe frequency excursions could be expected. Ovefrequency could 


\section{ASSESSMENT OF THE ELECTRIC SYSTEMS INTERCONNECTION}

arise after total or partial tripping of the interconnection. In these cases, the turbine governors are the only devices capable of controlling and restoring the system frequency, provided that no special system control action was taken, such as generator tripping or increasing the available transmitted power.

On the other hand, the underfrequency conditions, which might arise due to some disturbances such as the loss of generation units can be easily controlled by shedding some loads according to the system's load shedding scheme. The agreement on a load shedding scheme, common to all connected systems is considered one of the important issues which should be reached immediately after putting all interconnection links in operation. The tripping of some lines, included in the interconnection, will eventually cause some islanding of specific systems with loads of other grids. It is necessary in these cases to decide the criterion on which the tripping scheme has been based, to avoid complicated schemes and unnecessary shedding of some loads. Table 2 provides some Figures for the expected future load shedding scheme.

Table 2: Load shedding scheme for the current constituents of the EIJLST.

\begin{tabular}{|c|c|c|c|c|}
\hline Frequency & Egypt & Jordan & Syria & Turkey \\
& & & & \\
\hline 49.2 & $2 \%$ & & & \\
49.1 & $3 \%$ & & $8 \%$ & $8 \%$ \\
49 & $4 \%$ & $8 \%$ & & $10 \%$ \\
49 & Link Tripping & & $10 \%$ & $15 \%$ \\
48.8 & 10 & $10 \%$ & & \\
48.7 & 20 & $15 \%$ & $15 \%$ & $15 \%$ \\
48.6 & 20 & Link Tripping & Tripping \\
48.5 & & $2 \%$ & $15 \%$ & \\
48.4 & & $3 \%$ & & \\
48.2 & & $2 \%$ & & \\
48 & & $3 \%$ & & \\
47.9 & & $4 \%$ & & \\
47.8 & & $4 \%$ & & \\
47.7 & & & & \\
47.6 & & & & \\
& & & & \\
\end{tabular}

\subsection{Generating Units}

The generating units in interconnected systems have to be operated according to some specific conditions. These conditions concern sensitivity to frequency, voltage deviations and the means to control active and reactive power. Since the power frequency is common to all units and any drop in this frequency due to a loss of generation will influence the whole system, it is vital that all interconnection parts should satisfy certain requirements with respect to frequency (E.S.Ibrahim, 1996). If this factor has not been given the required attention, the most sensitive units may trip causing further frequency decay, and in worst cases, this could be developed to cascade tripping and blackout.

Regarding the voltage variations, the short duration dips to certain levels should not cause tripping of the unit. The control facilities should be set to keep these units running with the highest reliability. This, in fact, depends to some extent on the strength of the system. Therefore, when the generator is connected to a weak system, the machine voltage is controlled by the automatic excitation system. However, the speed governor has the responsibility of controlling the machine speed and consequently the system 


\section{M.H. ABDERRAZZAQ}

frequency. On the other hand, if the generator is connected to a strong system the machine voltage and system frequency is almost constant. Consequently, the role of the automatic excitation control is to fix the reactive power supplied by the generator to the network.

\subsection{Protection System Coordination.}

The main aim of the protection system is to trip the faulty elements in the network and to maintain a high level of continuous service. However, the requirements for the protection can be extended to cover more strategic goals such as utilization of reactive power compensators, power exchange and load shedding schemes. Since the protection philosophies employed by individual systems are different from one system to another, the integration of these systems into a common link will not be an easy task. The settings of the protective relays and their coordination procedures should be studied carefully prior to the commercial operation of the link. Moreover, the backup protection system of the main transmission lines should also be reviewed by all terminals of the interconnection. Finally, the difference in the design and the manufacture of the protective equipment, employed by various systems involved in the link, can cause some difficulties and false operations of the protective relays of connected countries. This needs careful assessment of the problem and the problem can be avoided by using unified standards for the equipment in the future.

\section{Conclusions}

To effectively utilize the existing energy resources in the Arab countries, it would be necessary to plan the system at a national level and to support the inter-regional links to form a unified regional power grid. The integration of individual systems into a single grid is associated with new technical problems. Although these difficulties are manageable, they must be seriously studied during the preparation stage of interconnection. This can be achieved by using advanced simulation techniques, computer facilities and other power related software. The deep investigation of these technical problems will protect the national grids from frequent disconnections and prevents repeated islanding from the main link.

The interconnection should be employed to unify the power systems in the region in respect of standardization, high voltage equipment selection and construction. The development of the individual electric systems should come as a first and necessary step before interconnection. This comprises the updating of the network configuration, system control and protection, which are necessary for the stability and robustness of future interconnection network.

\section{References}

ABDERRAZZAQ, M. and ALZAHAWI, B., 1996. The Jordan-Egypt Red Sea Cable Interconnection Project. Proceedings of the sixth IEE Conference "AC and DC Power Transmission Conference" Publication No 423, 29Apr-3May 1996, London, 124-127.

AMRO, K., (Editor). 1997. Electrical Energy Bulletin of the Arab Countries. Arab Union of Producers, Transporters and Distributers of Electricity. Amman, Jordan.

EDF Report, 1998. Operational Studies for the interconnection of the power systems of the EIJLST Countries.

GOUWS, M., 1999. Egyptian Power Surge. African Energy Magazine,1, No1,South Africa.

IBRAHIM, E.S., 1996. Interconnection of Electric Power Systems in the Arab World. IEE Power Engineering Journal, 121-127.

SACKEY, T. and ZAKHARY, S.Z., 1996. Power Wheeling Through the West African Interconnected System. Proceedings of the sixth IEE Conference "AC and DC 
ASSESSMENT OF THE ELECTRIC SYSTEMS INTERCONNECTION

Power Transmission Conference" Publication No 423, 29Apr-3May, 1996, London, 13-18.

Received 22 June 2001

Accepted 13 December 2001 